\title{
MENSURAÇÃO DAS VANTAGENS COMPETITIVAS DO CAPITAL INTELECTUAL: ESTUDO EM UMA COOPERATIVA DE CRÉDITO NO SUL DO \\ BRASIL
}

MEASUREMENT OF COMPETITIVE ADVANTAGES OF INTELLECTUAL CAPITAL: STUDY IN A CREDIT COOPERATIVE IN THE SOUTH OF BRAZIL

\author{
NATHALIA BERGER WERLANG ${ }^{1}$ \\ ATAIDE VIEIRA DE SOUZA JUNIOR ${ }^{2}$
}

RESUMO: O propósito deste artigo é mensurar o impacto do capital intelectual sobre a vantagem competitiva, a partir da visão dos colaboradores de uma cooperativa de crédito e de investimento do sul do país. Embora este tema tenha sido amplamente estudado, a maior parte dos trabalhos têm se concentrado nos aspectos específicos do capital intelectual. Para a execução deste estudo, foi realizada uma pesquisa com os colaboradores de uma cooperativa de crédito e de investimento do sul do país com uma amostra de 100 colaboradores. A fim de atingir os objetivos da pesquisa, foi desenvolvido um estudo de natureza descritiva e de abordagem quantitativa, operacionalizado por meio de uma survey. Por meio de análises estatísticas univariadas e de correlação, foi possível identificar que o capital intelectual possui influência sobre a vantagem competitiva da cooperativa em estudo. Além disso, destaca-se práticas relevantes da cooperativa, a qual busca o conhecimento mútuo para a resolução de questões do cotidiano de trabalho, e dispõe de mecanismos e setores especializados a fim de difundir o conhecimento como forma de melhoria na organização.

Palavras-chave: Capital intelectual, Vantagem competitiva, Cooperativa de crédito e de Investimento.

ABSTRACT: The purpose of this article is to measure the impact of intellectual capital on competitive advantage, from the perspective of the employees of a credit and investment cooperative in the south of the country. While this theme has been extensively studied, most papers have focused on the specifics of intellectual capital. For the execution of this study, a research was carried out with the collaborators of a credit and investment cooperative in the south of the country with a final sample of 100 employees. In order to achieve the objectives of the research, a descriptive and quantitative approach was developed, which was implemented through a survey. Through univariate statistical analysis and correlation, it was possible to identify that intellectual capital has influence on the competitive advantage of the cooperative under study. In addition, it highlights relevant practices of the cooperative, which seeks mutual knowledge to solve daily work issues, and has mechanisms and specialized sectors in order to disseminate knowledge as a way of improving the organization.

Keywords: Intellectual capital, Competitive advantage, Credit and investment cooperative.

Data de submissão: 20/11/2016 Data de aceite: 18/09/2018 Data de publicação: 18/09/2018

1 Doutoranda em Administração na Universidade Federal de Santa Catarina (UFSC). Professora titular no Centro Universitário FAI (UCEFF). Diretora presidente do Instituto de Desenvolvimento Regional FAI - IFAI.

2 Acadêmico do Centro Universitário FAI (UCEFF) 


\section{INTRODUÇÃO}

O capital intelectual é um importante recurso de uma organização, e pode ser associado e explicado como a sociedade do conhecimento ou a valorização do conhecimento como recurso econômico somando-se às tecnologias disponíveis empregadas para garantir a sua continuidade. Assim, esses benefícios intangíveis se tornam uma vantagem competitiva sobre as demais organizações.

Nas últimas décadas surgiram vários conceitos sobre capital intelectual, porém ainda não existe um consenso sobre a sua conceituação ou mesmo quanto a sua denominação e entendimento. Muitos estudos nas áreas de contabilidade, economia e administração de empresas vem sendo realizados com enfoques diferentes, sendo o capital intelectual predominantemente tratando como recurso econômico nas organizações, já que contribui para a melhoria de seus desempenhos (ANTUNES; MARTINS, 2007).

O presente estudo segue o conceito de Coser (2012), o qual divide o capital intelectual em Capital Humano, Capital Relacional e Capital Estrutural, somando habilidades, conhecimentos, relacionamentos e atitudes das pessoas, à dados, rotinas, patentes, manuais e relacionamentos entre as organizações e os empregados.

Diante da intensa concorrência global, há um reconhecimento generalizado de que o capital intelectual é uma força crítica que impulsiona o crescimento econômico, dentro desse contexto, este trabalho parte da seguinte pergunta de pesquisa: qual é o impacto da gestão do capital intelectual sobre a vantagem competitiva de uma cooperativa de crédito?

Buscando responder tal questão, este estudo tem como objetivo mensurar o impacto do capital intelectual sobre a vantagem competitiva, a partir da visão dos colaboradores de uma cooperativa de crédito e de investimento do sul do país.

A Cooperativa de crédito e de investimento é uma instituição financeira cooperativa formada pela associação de pessoas para prestar serviços financeiros exclusivamente aos seus associados. Os cooperados são ao mesmo tempo donos e usuários da cooperativa, participando de sua gestão e usufruindo de seus produtos e serviços.

Nas cooperativas de crédito e de investimento, os associados encontram os principais serviços disponíveis nos bancos, tais como: conta corrente, aplicações financeiras, cartão de crédito, empréstimos e financiamentos. Os associados têm poder igual de voto independentemente da sua cota de participação no capital social da cooperativa. 0 cooperativismo não visa lucros, os direitos e deveres de todos são iguais e a adesão é livre e voluntária.

As cooperativas de crédito e de investimento são autorizadas e supervisionadas pelo Banco Central, ao contrário dos outros ramos do cooperativismo, tais como transporte, educação e agropecuária. Os depósitos em instituições desta natureza têm a proteção do Fundo Garantidor do Cooperativismo de Crédito (FGCoop). Esse fundo garante os depósitos e os créditos mantidos nas cooperativas singulares de crédito e nos bancos cooperativos em caso de intervenção ou liquidação extrajudicial dessas instituições. Atualmente, o valor limite dessa proteção é o mesmo em vigor para os depositantes dos bancos.

Nesse contexto, buscou-se enquadrar o tema capital intelectual em uma Cooperativa de Crédito e de Investimento do Sul do país com todos os seus nuances, verificando-se assim as necessidades de implementação da gerência do conhecimento, apontando os pontos positivos e negativos relacionados a este tema. 
Dessa forma, a presente pesquisa compõe-se das seguintes partes: (2) capital intelectual: aborda a evolução histórica, os conceitos e a importância do capital intelectual e as abordagens e conceitos da vantagem competitiva, assim como da questão do capital intelectual como fonte de vantagem competitiva também os últimos estudos referente ao capital intelectual; (3) metodologia: apresenta a metodologia do estudo; (4) análise dos dados: apresenta a análise dos dados coletados, dimensão do capital humano, capital estrutural, capital relacional e vantagem competitiva; (5) conclusões e recomendações.

\section{FUNDAMENTAÇÃO TEÓRICA}

\subsection{CAPITAL INTELECTUAL: EVOLUÇÃO HISTÓRICA E PRINCIPAIS CONCEITOS}

O capital intelectual é um bem intangível dentro de uma instituição, e manifesta-se nas pessoas sendo a soma das suas habilidades, conhecimentos, atitudes e relacionamentos interpessoais. Já no contexto organizacional, o capital intelectual representa os recursos intangíveis que produzirão ativos de alto valor para a empresa. Atualmente o capital intelectual é estudado por diversos pesquisadores, sendo considerado de elevada importância não somente para as pessoas, mas principalmente para as empresas e demais organizações (ANTUNES; MARTINS, 2007).

Historicamente, o capital intelectual foi citado pela primeira vez em 1969 na obra de John Kenneth Galbraith, o qual incorporava um grau de "ação intelectual" da pessoa, ou seja, a capacidade do colaborador de aplicação do seu conhecimento e habilidades, não considerando simplesmente o intelecto. Em 1974, Flamhotz publicou a obra Human Resource Accounting que até hoje é considerada um marco no tema capital intelectual (VAZ et al., 2015).

Com o tempo e a evolução das empresas no mercado de consumo, surgiu a necessidade de mensuração do capital intelectual, sendo que em 1991 uma empresa sueca denominada Skandia criou o cargo de diretor de capital intelectual, tornando-se a pioneira mundial na mensuração de capital intelectual através da percepção da sua importância no cenário econômico, publicando o primeiro relatório em 1994. Seguindo os mesmos passos, em 1995, a empresa Celemi, também sueca, criou a "auditoria do conhecimento", destacando a importância do capital intelectual para o desenvolvimento das organizações (REINA et al., 2009).

No final da década de 90, o uso do termo capital intelectual deixou de ser algo estranho na academia, e começou a fazer parte dos assuntos de vários palestrantes e estudiosos da área, a exemplo do primeiro simpósio internacional sobre capital intelectual em 1999 organizado pela OECD em Amsterdã (REINA et al., 2009).

Os primeiros dez anos da temática capital intelectual constituiu uma experiência interessante que inspirou tanto as organizações, no que se refere à identificação, mensuração e administração dos seus bens intangíveis, quanto os pesquisadores dentro da sistematização e estabelecimento da base para este tema emergente, que aos poucos foi se tornando cada vez mais difundido e apreciado (ENSSLIN et al., 2008).

Os estudos sobre o tema vêm seguindo uma evolução lógica, isso porque, as necessidades das organizações no século passado eram, na grande maioria, o esforço físico para operar as máquinas, porém, atualmente, o diferencial de uma organização é o conhecimento agregado ao conjunto de pessoas, ou seja, o capital intelectual da organização (REIS, 2005). 
O capital intelectual constitui um indicativo de um valor futuro em uma organização, sendo caracterizado como a capacidade dos seus colaboradores em gerar resultados financeiros. De outro norte, o capital patrimonial de uma empresa, pode ser mensurado através de um valor contábil do seu patrimônio líquido. Assim, através da popularização do capital intelectual neste último século, é comum uma empresa gastar mais dinheiro para recrutar, selecionar, contratar e treinar seus colaboradores, do que o investimento em máquinas e equipamentos do Capital Patrimonial (REIS, 2005).

Para Coser (2012), o capital intelectual pode ser dividido em três elementos: Capital Humano; Capital Relacional e Capital Estrutural.

O Capital Humano é o conjunto de habilidades, conhecimentos, relacionamentos e atitudes das pessoas que contribuem para o crescimento da organização; Capital Estrutural é a própria estrutura organizacional, baseada em dados, rotinas, patentes, manuais, etc.; por fim, Capital Relacional que é o conhecimento derivado dos relacionamentos entre as organizações e os empregados, ou seja, uma troca de experiências e conhecimentos entre pessoas e organizações (COSER, 2012).

Assim, tem-se que o capital intelectual é um bem intangível importantíssimo para o desenvolvimento de uma empresa, porém, de nada adianta uma empresa ter colaboradores com alto nível de conhecimento se trabalham de forma isolada, logo, é necessário que haja compartilhamento e transmissão do conhecimento pertencente a cada um para que assim seja possível transformar esse bem intangível em ativos financeiros para a empresa (COSER, 2012; BERTOLA et al., 2015).

\subsection{VANTAGEM COMPETITIVA}

Na sociedade atual, o papel de gerar toda a riqueza e poder das organizações deixou de ser exclusividade dos fatores tradicionais de produção, tais como: poder do homem, utilização de recursos naturais, mão de obra e capital. Nesse contexto, emerge a importância de fatores de produção intangíveis, tais como: a informação, o capital intelectual e o conhecimento.

De acordo com Leite e Porsse (2003), a vantagem competitiva pode ser conceituada como a ocorrência de níveis de performance econômica acima da média do mercado em virtude das estratégias diferenciadas adotadas pelas empresas.

Em plena ascensão do capital intelectual nas empresas, faz-se necessária a aplicação de modelos analíticos e estudos empíricos que explorem as implicações práticas dos processos envolvidos na criação do conhecimento para o acúmulo de capacidades que possam conduzir as empresas a um melhor desempenho (CENTENARO et al., 2015).

Hoje, muitos gestores têm tentado, com sucesso parcial, capturar os ativos do conhecimento centralizando as funções de gestão do conhecimento em um setor específico, como pesquisa e desenvolvimento e/ou recursos humanos, ou investindo em Tecnologia da Informação e Comunicação (TIC). Entretanto, apesar dos esforços, é possível identificar que existem gestores que desconhecem como as empresas podem utilizar o conhecimento em prol de melhores desempenhos. Assim, surge a necessidade de as empresas e seus gestores diferenciarem a gestão do conhecimento do capital intelectual, agregando ambas para melhorar suas práticas, inovando e respondendo mais rapidamente ao mercado (ZHENG et al., 2010).

O capital intelectual em uma empresa tem como consequência lógica vantagens competitivas, as quais são fundamentais nos dias atuais, já que há uma demanda crescente 
de produtos e serviços de qualidade pelos consumidores. Nesse sentido, as organizações precisam buscar maneiras de desenvolver uma relação a longo prazo com seus clientes, tornando-os fieis, proporcionando a eles uma boa oferta de produtos e serviços (BERTOLA et al., 2015).

Por fim, é importante que as empresas estejam dispostas a investir em capital intelectual, não somente para a busca de aperfeiçoamento de seus produtos e serviços, mas também pelas vantagens relacionadas à competitividade em um mercado de consumo cada vez mais exigente (BERTOLA et al., 2015).

\subsection{PESQUISAS RECENTES SOBRE CAPITAL INTELECTUAL}

Por tratar-se de um tema de alta importância competitiva, o capital intelectual vem sendo estudado e difundido por diversos autores, os quais contribuíram para a melhor compreensão do tema, conforme apresentação a seguir.

Dentre os estudos mencionados, pode-se citar a denominada "a influência do capital intelectual sobre a performance dos projetos de software", no periódico Revista Perspectivas em Gestão \& Conhecimento. Esta pesquisa busca mensurar qual a importância do capital intelectual no desenvolvimento de Software por meio de um modelo teórico para descrever os elementos do capital intelectual agregada à performance dos projetos de software (COSER et al., 2013).

A pesquisa bibliográfica foi o método essencial empregado na seleção e elaboração dos construtos do modelo, bem como na formulação das relações de dependência entre estes. Foi aplicado um questionário para empresas do polo da base tecnológica da Grande de Florianópolis, em Santa Catarina. De um total de empresas entrevistadas, foram selecionadas 180 cuja atuação inclui a atividade de desenvolvimento de software (COSER et al., 2013).

Para Coser et al. (2013) os resultados do modelo estatístico revelam que os três elementos do capital intelectual: Capital Humano, Estrutural e Relacional, exercem influências positivas e significativas sobre a performance dos projetos, sendo mais determinantes o Capital Humano e o Capital Estrutural. Constata-se, ainda, que o nível de Capital Humano é positivamente correlacionado com os níveis de Capital Estrutural e de Capital Relacional nos projetos, confirmando a teoria de que o capital intelectual gera valor para as organizações quando seus três elementos interagem e se desenvolvem mutuamente.

Em outra recente pesquisa, foi publicado o artigo denominado "contribuição do capital intelectual no compartilhamento do conhecimento em uma rede de ensino superior privada", no periódico Revista de Gestão e Tecnologia. O objetivo desta pesquisa foi analisar o compartilhamento do conhecimento para tomada de decisões em uma Instituição de Ensino Superior Privada, levando em consideração os elementos do capital intelectual, ou seja, capital humano, estrutural e relacional. A pesquisa foi quantitativa, sendo aplicado um questionário para 13 coordenadores de cursos de graduação em uma amostra do tipo probabilística e não intencional em uma Instituição de Ensino Superior Privada com Campus em uma das Capitais da região Sul do País (TEODOROSKI et al., 2013).

Segundo Teodoroski et al. (2013) o resultado foi que o capital intelectual contribui para o compartilhamento do conhecimento e tomada de decisões, principalmente no que se refere ao capital estrutural. Os coordenadores também informaram que acessam o Sistema de Gestão do Conhecimento e o Sistema de Informações Acadêmico, com isso a pesquisa 
concluiu que o capital intelectual e os instrumentos da gestão empresarial podem contribuir de forma positiva para a gestão e compartilhamento do conhecimento.

Já no estudo de Carlos Filho et al. (2014) buscou-se verificar se existe diferença significativa entre os micro e pequenos empreendedores que possuem familiaridade e os que não possuem acerca dos termos ativos intangíveis e/ou capital intelectual, nesse sentido, foi publicado o artigo denominado "importância e contribuição do ativo intangível: percepção dos empreendedores de micro e pequenas empresas sobre o capital intelectual", publicado no periódico "Revista de Organizações e Contexto". A amostra compreendeu 84 empreendedores de micro e pequenas empresas que estavam participando da Feira do Empreendedor organizada pelo SEBRAE em Recife/PE, em outubro de 2012.

Das pesquisas já realizadas, constatou-se que metade dos entrevistados nunca ouviram falar de capital intelectual. De outro norte, os que demonstraram conhecer o tema responderam que este é essencial, importante ou muito importante para as organizações. Os resultados também apontaram que os empreendedores que têm familiaridade com os termos "capital intelectual" e/ou "ativo intangível" tendem a atribuir maior nível de importância aos elementos do capital intelectual, além disso, 47,79\% responderam que produtos, serviços e funcionários são importantes para adicionar valor a empresa e contribuir para aumentar as vantagens competitivas (CARLOS FILHO et al. 2014).

O estudo de Oliveira Filho et al. (2014) teve como propósito medir o impacto da gestão do capital intelectual na vantagem competitiva de uma organização, para isso foi aplicado um questionário através do e-mail corporativo da Universidade Corporativa do Grupo Algar, onde 105 sujeitos responderam. Nessa pesquisa participaram diretores, gerentes, coordenadores e supervisores. Tal artigo, denominado "efeito da gestão do capital intelectual na vantagem competitiva: o caso de um grupo empresarial com atuação predominante em tecnologia", no periódico Revista Gestão Organizacional, demonstrou a importância do capital intelectual como vantagem competitiva.

Para a pesquisa supramencionada, identificaram-se fortes influências positivas entre capital humano e capital estrutural na vantagem competitiva da empresa. De outro lado, o capital relacional teve moderada influência positiva, da mesma forma, as demais variáveis do estudo também tiveram influências moderadas e positivas (OLIVEIRA FILHO et al., 2014).

A pesquisa de Oro et al. (2014) buscou a relação do capital intelectual de natureza social e ambiental com o desempenho econômico financeiro do segmento de energia elétrica brasileiro, sendo publicada no periódico Revista de Administração da UFSM, nessa pesquisa verificou-se a relação entre os indicadores de capital intelectual de natureza social e ambiental e as variáveis de desempenho econômico-financeiro das empresas listadas no Índice de Sustentabilidade Empresarial (ISE) da BM\&FBovespa em 2010 e 2011, sendo analisadas 11 empresas deste setor.

As variáveis de análise partiram do constructo capital intelectual social e capital intelectual ambiental, conforme proposto por Guthrie et al. (1999) e adaptado por Silva e Ensslin (2011). Os resultados indicam que as empresas analisadas que investiram em capital intelectual social e ambiental tiveram uma evolução positiva de um ano para outro, ou seja, um desenvolvimento econômico-financeiro (ORO et al. 2014).

Por fim, a pesquisa mais recente que foi publicada no periódico Revista Contemporânea de Economia e Gestão, intitulada "efeitos do capital intelectual sobre o desempenho financeiro em empresas brasileiras e chilenas", teve como objetivo verificar a influência do capital intelectual medido pelo valor agregado do capital intelectual (VACI). Nessa pesquisa buscou-se mensurar o desempenho financeiro em empresas brasileiras e 
chilenas no ano de 2013, a metodologia utilizada foi descritiva, documental e com abordagem quantitativa por meio da técnica estatística "correlação canônica". A base de dados utilizadas foi a Tomnson ${ }^{\circledR}$, sendo analisadas 303 empresas. Os resultados dos estudos demonstraram correlação canônica existente entre as variáveis que compõem o $\mathrm{VACl}$ com as variáveis de desempenho financeiro tanto no Brasil como no Chile. O resultado da pesquisa foi que o capital intelectual influencia significativamente o desempenho financeiro das empresas brasileiras e chilenas (TURRA et al., 2015).

Com base nas pesquisas mencionadas, verifica-se que empresas que tiveram um investimento e desenvolvimento do capital intelectual, obtiveram como resultado vantagens competitivas, tomadas de decisões mais precisas e consequentemente um maior resultado financeiro.

\section{METODOLOGIA}

Quanto à abordagem, este trabalho trata-se de uma pesquisa quantitativa, porque traduz em números as opiniões e as informações, utilizando de recursos e técnicas estatísticas (RICHARDSON, 2011). Nesta abordagem, foram analisados os dados levantados sobre capital intangível e sua influência na vantagem competitiva da organização.

Segundo Gil (2010), é característica dessa técnica o desenvolvimento de estudos e pesquisas autoadministradas, de modo que o pesquisado não conta com auxílio do pesquisador. A pesquisa através de survey caracterizada pela interrogação direta das pessoas cujo comportamento se deseja conhecer, procedendo-se a solicitação de informações a um grupo de pessoas sobre o problema pesquisado para, em seguida, mediante uma análise quantitativa, se extrair conclusões dos dados coletados.

O universo da pesquisa abrange os funcionários de uma Cooperativa de Crédito e de Investimento com 25 anos de existência, que possui sua sede no Sul do país, mas que atua nos estados de São Paulo, Paraná e Santa Catarina, contando com cerca de 300 funcionários.

O projeto de pesquisa foi elaborado e remetido ao Comitê de Ética em Pesquisa da FAI Faculdades de Itapiranga (CEP - FAI), o qual procedeu à sua aprovação. $O$ instrumento de coleta de dados foi construído na web utilizando-se a plataforma Survey Monkey, sendo que o link foi enviado por um e-mail corporativo da cooperativa de crédito. A pesquisa deu-se no mês de setembro de 2016. A primeira seção fez um levantamento da caracterização do local de trabalho (unidade ou SUREG) e do entrevistado (gênero, idade, escolaridade, área de formação, área/departamento, cargo e tempo de empresa/sistema). Da segunda à quarta seção, medir-se-á o ponto de vista dos entrevistados a respeito do Capital Humano (7 questões); do Capital Estrutural (7 questões); do Capital Relacional (6 questões) e da Vantagem Competitiva (8 questões). Cada questão será medida em termos de sete pontos da Escala Likert, de 1 (discordo totalmente) até 7 (concordo totalmente).

A população pesquisada corresponde ao total dos funcionários da Cooperativa de Crédito e de Investimento, entretanto, aderiram à pesquisa 100 respondentes, não havendo questionário incompleto, de modo que o total-final da amostra corresponde a 100 participantes, representando $33 \%$ da população.

O questionário utilizado foi adaptado da obra de Bataineh e Zoabi (2011), intitulada de "The Effect of Intellectual Capital on Organizational Competitive Advantage: Jordanian Commercial Banks (Irbid District) An Empirical Study". Ressalta-se que o questionário foi adaptado para sua melhor aplicação na presente pesquisa, uma vez que foi aplicado para os colaboradores de uma cooperativa de crédito e de investimento. 
O questionário foi instrumentalizado por meio da companhia de desenvolvimento de pesquisas online SurveyMonkey. Os dados foram tabulados e analisados por meio do software estatístico SPSS.

Inicialmente foram os dados foram analisados de forma descritiva, por meio de frequência e percentual do perfil da amostra. Já para as análises da segunda a quarta seção foram utilizadas as técnicas estatísticas a) análise fatorial e b) correlação (HAIR et al., 2005).

A análise fatorial exploratória (AFE), foi realizada para reduzir as variáveis a dimensões (HAIR et al., 2005). Assim, foram extraídos os fatores a partir das variáveis que compõem as dimensões do capital intelectual e a vantagem competitiva. Após, aplicou-se, então, a técnica de correlação para verificar a intensidade da relação entre os construtos.

\section{ANÁLISE DOS DADOS}

Os sujeitos participantes deste estudo são colaboradores da Cooperativa de Crédito e de Investimento pesquisada, sendo que $17(17 \%)$ respondentes trabalham a Superintendência Regional - SUREG e outros 83 (83\%) nas Unidades de Atendimentos - Uas. De os respondentes, 60 (60\%) atuam na área de negócios, 35 (35\%) que atuam na área administrativa e os demais (5\%) atuam em outros setores da Instituição, tais como: setor jurídico, $\mathrm{TI}$, comunicações e gestão de pessoas.

Dentre os cargos dos respondentes, destaca-se uma maior participação de Gerente de Negócios com 26 (26\%), em seguida, Assistente de Atendimento/Negócios com 21 (21\%) e Auxiliar/Assistente Administrativo com 19 (19\%) dos respondentes. Destaca-se que houve uma grande participação dos cargos da alta gerencia nesta pesquisa, tais como: Gerentes de Unidade de Atendimento, Coordenador/Gerente Administrativo, Assessores e Diretor/Presidente, fato que contribui positivamente à pesquisa, dado o número reduzido de caros de gerência.

Quanto ao gênero, 59\% (59) dos respondentes são do gênero feminino e 41\% (41) são do gênero masculino. Os respondentes com menor idade possuíam 19 anos, já o com maior idade possui 58 anos. Destaca-se que a $75 \%$ dos respondentes possuem faixa etária de 19 a 35 anos.

Em relação ao nível de escolaridade dos respondentes, destaca-se que 55 (55\%) destes possuem MBA/Especialização, outros 33 (33\%) possuem apenas Graduação, por fim, 12 (12\%) estão concluindo a sua Graduação.

Dos 100 respondentes, 71 (71\%) deles cursaram ou estão cursando Administração, 18 (18\%) Contabilidade e 11 (11\%) outros cursos, tais como: Direito, Economia, Ciências da Computação, dentre outros.

Além disso foi avaliado o tempo de empresa dos participantes. Nesse sentido, observa-se que 22 (22\%) participantes têm de 3 a 5 anos de atuação na empresa; 29 (29\%) respondentes têm entre 5 e 10 anos de atuação na empresa; 27 (27\%) respondentes têm entre 10 e 20 anos de empresa e 2 (2\%) respondentes tem mais de 20 anos de empresa. Dessa forma, considerando que esta Cooperativa de Crédito e de Investimento tem apenas 25 anos de fundação, é significativo o número de colaboradores com mais de 3 anos de trabalho e dedicação à empresa, correspondendo a 80 (80\%) respondentes, ou seja, $80 \%$ dos colaboradores tem acima de 3 anos de empresa, sendo que apenas 20 (20\%) respondentes tem menos de 3 anos.

Esta análise de dados sobre o perfil dos entrevistados, demonstra que a Cooperativa de Crédito e de Investimento possui um alto índice de colaboradores com Graduação MBA e 
Especialização chegando a $88 \%$ trazendo grandes conhecimentos à instituição. Além disso, $80 \%$ dos colaboradores respondestes possuem mais de 3 anos de trabalho na instituição, o que nos leva a crer que a equipe possui um alto grau de conhecimento compartilhado, habilidades e experiência de todos os empregados.

Contudo, esse perfil caracterizado por alto grau de escolaridade, tempo de experiência, formação técnica e conhecimentos compartilhados não significa necessariamente vantagem competitiva, pois, conforme aponta Sharon (2007), a maioria dos profissionais que possuem conhecimentos especializados e realizam uma produção intelectual de alta qualidade tende a controlar o domínio de seu trabalho, mas pode não apoiar os objetivos organizacionais. Assim, é necessário que o grupo pesquisado saiba desenvolver as melhores práticas para gerenciar o seu capital intelectual, a fim de construir e sustentar uma vantagem competitiva em longo prazo.

A seguir serão apresentados os resultados da análise descritiva acerca das dimensões do capital intelectual (capital humano, capital estrutural e capital relaciona), assim como a análise do construto da vantagem competitiva.

\subsection{ANÁLISE DESCRITIVA DA DIMENSÃO CAPITAL HUMANO}

A Tabela 1 apresenta inicialmente os resultados para o capital humano. Considerando a escala Likert, a qual varia de 1 a 7, tendo como média 3,5\%, constatou-se que o menor resultado obtido na presente pesquisa foi o de 4.92, o que demonstra que a Cooperativa estudada possui bons resultados.

Conforme demonstra a Tabela 1, a dimensão Capital Humano obteve uma média igual a 5,34, sendo que o item com maior média $(5,49)$ é o item 1 , denominado: "As competências humanas dentro da empresa são utilizadas pela gerencia" - com desvio padrão de 1,283 , demonstrando que a instituição pesquisada possui gerentes que utilizam das competências, habilidades e experiência de seus colabores para desenvolvimento das atividades e aferimento das metas propostas. Este direcionamento da força de trabalho visando o incremento do capital humano constitui um grande desafio para organizações, que podem lançar mão de estratégias para o desenvolvimento dos recursos humanos ou para a atração de novos colaboradores com altos níveis de conhecimentos e habilidades (YOUNDT 2004).

Tabela 1 - Estatística descritiva do capital humano

\begin{tabular}{lcc}
\hline Afirmativa & Média & Desvio Padrão \\
\hline $\begin{array}{l}\text { 1. As competências humanas dentro da empresa são utilizadas pela } \\
\text { gerencia }\end{array}$ & 5,49 & 1,283 \\
$\begin{array}{l}\text { 2. O conhecimento humano dentro da empresa é utilizado pela gerencia } \\
\text { 3. As capacidades humanas dentro da empresa são utilizadas pela } \\
\text { gerencia }\end{array}$ & 5,48 & 1,367 \\
$\begin{array}{l}\text { 4. Os nossos colaboradores são considerados os melhores nos nossos } \\
\text { serviços }\end{array}$ & 5,38 & 1,316 \\
$\begin{array}{l}\text { 5. Os nossos colaboradores são especialistas em seu trabalho e funções } \\
\text { 6. Os nossos colaboradores desenvolvem novas ideias e lnovação }\end{array}$ & 5,14 & 1,077 \\
7. O nosso ambiente organizacional e valores partilhados fornecem \\
grande apoio à inovação
\end{tabular}

Fonte: Dados da pesquisa (2016) 
O capital humano é muito importante para as organizações porque é a partir dele nasce a inovação e a renovação das ideias, já que a capacidade e a criatividade são características inerentes do ser humano, podendo dessa forma tanto revolucionar pequenos processos como criar macroestratégias para otimizar os lucros nas organizações (STEWART 1998).

O item com menor média registrado foi o 5, denominado: "Os nossos colaboradores são especialistas em seu trabalho e funções" - apresentando média de 5,14, o que demonstra satisfação quanto ao conhecimento aplicado dos colaboradores, já que está acima da média que é 3.5\%.

De modo geral, mesmo tendo $88 \%$ de colaboradores com nível de escolaridade igual ou superior a graduação e $80 \%$ ter mais de 3 anos de empresa, a dimensão Capital Humano ficou com a menor média dentre os demais pesquisados. Dessa forma, surge a necessidade para o desenvolvimento desse capital e consequentemente, o desenvolvimento da gestão do conhecimento na Cooperativa de Crédito e de Investimento.

\subsection{DIMENSÃO CAPITAL ESTRUTURAL}

A Tabela 2 apresenta os resultados de média e desvio padrão para os dados de capital estrutural. Conforme apresentado na Tabela 2, a dimensão Capital Estrutural, obteve uma pequena vantagem sobre a dimensão Capital Humano, ficando com uma média igual 5,40. O item com maior média foi o 11 , denominado: "A nossa cultura da organização contém ideias valiosas da forma de fazer negócios", apresentando média de 5,67 com desvio padrão de 1,055, logo, este item reforça ainda mais a ideia de Cooperativa em diferenciação as demais Instituições Financeiras, pois trabalha fortemente com a cultura da organização e ajuda mutua, fazendo ligação com Stewart (1998), onde menciona que o capital estrutural é o componente do capital intelectual que "pertence à empresa como um todo, podendo ser reproduzido e divido".

Tabela 2 - Estatística descritiva do capital estrutural

\begin{tabular}{|c|c|c|}
\hline Afirmativa & Média & Desvio Padrão \\
\hline 8. A nossa organização tem unidades específicas que tratam & & \\
\hline o conhecimento & 5,13 & 1,502 \\
\hline 9. A nossa estrutura organizacional se ajusta de acordo com & & \\
\hline as mudanças ambientais & 5,24 & 1,280 \\
\hline $\begin{array}{l}\text { 10. A nossa organização incentiva a relação informal para a } \\
\text { troca de conhecimentos }\end{array}$ & 5,42 & 1,288 \\
\hline 11. A nossa cultura da organização contém ideias valiosas & & \\
\hline da forma de fazer negócios & 5,67 & 1,055 \\
\hline $\begin{array}{l}\text { 12. A nossa organização tem bases de dados suficientes e } \\
\text { de acesso a elas }\end{array}$ & 5,34 & 1,208 \\
\hline $\begin{array}{l}\text { 13. A nossa organização incorpora muito do seu } \\
\text { conhecimento e informação em estruturas, sistemas e } \\
\text { processos }\end{array}$ & 5,41 & 1,207 \\
\hline $\begin{array}{l}\text { 14. A nossa organização tem a sua própria rede de } \\
\text { comunicação para fora e para dentro que é útil para a troca } \\
\text { de conhecimento }\end{array}$ & 5,61 & 1,254 \\
\hline Média & 5,40 & \\
\hline
\end{tabular}

Fonte: Dados da pesquisa (2016) 
A menor média apresentada foi a descrita no item 8 - "A nossa organização tem unidades que tratam os conhecimentos", dessa forma, pode-se concluir que o conhecimento agregado deve ser mais difundido, pois é um fator que trará muitos benefícios à organização.

O Capital Estrutural é a própria estrutura organizacional, baseada em: dados, rotinas, marcas, imagens, manuais, sistemas de tecnologia da informação, dentre outros. De outra forma pode-se dizer o Capital Estrutural é a extensão e manifestação do Capital Humano. Pelo índice auferido (média de 5,40) pode-se concluir que há necessidade de algumas mudanças estratégicas afim de desenvolver esse item, para que haja um maior desenvolvimento da organização.

Para se manterem competitivas, as organizações precisam compartilhar os conhecimentos dos seus colaboradores para que estes conhecimentos se tornem da própria organização. Dessa forma, o conhecimento agregado se mantém mesmo após a perda de colaboradores importantes ou a quebra de algum contrato de fornecimento (PABLOS 2004).

\subsection{DIMENSÃO CAPITAL RELACIONAL}

Nesta seção são apresentados os resultados do capital relacional. A Tabela 3 sintetiza os resultados. Conforme apresentado na Tabela 3, a dimensão Capital Relacional obteve a maior média dentre todos os demais, ficando com 5,60. O item 15, denominado: "Os nossos colaboradores são capazes de colaborar uns com os outros para diagnosticar e resolver problemas", apresentou média igual a 5,86, o que demostra que existe realmente uma rede de relacionamento entre colaboradores bem fortalecida. Segundo Youndt et al. (2004), para que haja um bom relacionamento entre os colaboradores, deve haver também a partilha do conhecimento, tanto no âmbito interno das organizações, quanto no âmbito externo, ou seja, entre as organizações.

De acordo com Coser (2012), o Capital Relacional é o conhecimento derivado dos relacionamentos entre as organizações e os empregados, ou seja, uma troca de experiências e conhecimentos entre pessoas e organizações.

Tabela 3 - Estatística descritiva do capital relacional

\begin{tabular}{|c|c|c|}
\hline Afirmativa & Média & Desvio Padrão \\
\hline \multicolumn{3}{|l|}{ 15. Os nossos colaboradores são capazes de colaborar uns } \\
\hline com os outros para diagnosticar e resolver problemas & 5,86 & 1,092 \\
\hline \multicolumn{3}{|l|}{ 16. Os nossos colaboradores partilham informação e } \\
\hline aprendem uns com os outros & 5,85 & 1,184 \\
\hline \multicolumn{3}{|l|}{ 17. Os nossos colaboradores trocam e interagem ideias com } \\
\hline pessoas de diferentes áreas da empresa & 5,59 & 1,190 \\
\hline \multicolumn{3}{|l|}{$\begin{array}{l}\text { 18. A gerência da empresa incentiva os colaboradores a } \\
\text { desenvolverem suas próprias competências, capacidades, }\end{array}$} \\
\hline etc & 5,64 & 1,322 \\
\hline \multicolumn{3}{|l|}{$\begin{array}{l}\text { 19. A gerência oferece motivação e recompensas para a } \\
\text { troca de conhecimentos e informações entre os }\end{array}$} \\
\hline colaboradores & 4,92 & 1,522 \\
\hline \multicolumn{3}{|l|}{$\begin{array}{l}\text { 20. Os colaboradores utilizam o conhecimento para resolver } \\
\text { problemas e aproveitar as oportunidades que surgem no }\end{array}$} \\
\hline ambiente & 5,72 & 1,083 \\
\hline Média & 5,60 & \\
\hline
\end{tabular}

Fonte: Dados da pesquisa (2016) 
O item que obteve a menor média $(4,92)$ foi o 19 - "A gerência oferece motivação e recompensas para a troca de conhecimentos e informações entre os colaboradores" fazendo uma breve relação com o item 15 que obteve a maior média, verificou-se que existe auxílio e troca de conhecimento entre os colaboradores, dessa forma, auxiliando no desenvolvimento de suas atividades.

Por mais que a dimensão do Capital Relacional obteve a maior média dentre os outros, o item 19 supramencionado, apresentou a menor média, denotando-se com isso que deve haver um maior incentivo à troca de conhecimento entre os colaborares.

O capital relacional é extremamente importante para uma organização, contudo, o conhecimento inerente desta categoria é o mais difícil ser desenvolvido e capturado, justamente porque os colaboradores das organizações que detêm este conhecimento podem dissemina-la para outras organizações. Tais dificuldades fazem com que, muitas vezes, o capital relacional seja relegado ao segundo plano (BONTIS 1999).

\subsection{DIMENSÃO VANTAGEM COMPETITIVA}

A Tabela 4 apresenta os resultados da dimensão do Construto Vantagem Competitiva. De acordo com a Tabela 4, evidenciou-se uma variável que obteve uma média igual a 5,54 ficando um pouco abaixo da dimensão Capital Relacional, sendo o item 23 - "A vantagem competitiva de nossa organização gera valor para o associado" com a maior média de todos os itens, 5,93, demonstrando que a organização possui vantagem competitiva sobre as demais.

Tabela 4 - Estatística descritiva da vantagem competitiva

\begin{tabular}{|c|c|c|}
\hline Afirmativa & Média & Desvio Padrão \\
\hline $\begin{array}{l}\text { 21. A nossa organização atingiu a vantagem competitiva } \\
\text { devido à sua estratégia de liderança }\end{array}$ & 5,50 & 1,243 \\
\hline $\begin{array}{l}\text { 22. A nossa organização identifica oportunidades no } \\
\text { mercado compatíveis com os recursos e capacidades do seu } \\
\text { negócio }\end{array}$ & 5,58 & 1,139 \\
\hline $\begin{array}{l}\text { 23. A vantagem competitiva de nossa organização gera valor } \\
\text { para o associado }\end{array}$ & 5,93 & 1,047 \\
\hline $\begin{array}{l}\text { 24. A nossa organização está a desenvolver uma vantagem } \\
\text { competitiva para identificar seus concorrentes relevantes }\end{array}$ & 5,51 & 1,210 \\
\hline $\begin{array}{l}\text { 25. A nossa organização atingiu a vantagem competitiva } \\
\text { devido à sua estratégia de diferenciação } \\
\text { 26. A flexibilidade dos serviços é um dos recursos da nossa }\end{array}$ & 5,68 & 1,145 \\
\hline vantagem competitiva & 5,42 & 1,288 \\
\hline $\begin{array}{l}\text { 27. A velocidade da oferta de serviços permitiu atingir uma } \\
\text { vantagem competitiva } \\
\text { 28. A diversidade de produtos e de serviços da nossa } \\
\text { organização é um dos recursos da nossa vantagem } \\
\text { competitiva }\end{array}$ & 5,12 & 1,386 \\
\hline Média & 5,54 & \\
\hline
\end{tabular}

Fonte: Dados da pesquisa (2016)

O item 27, denominado: "A velocidade da oferta de serviços permitiu atingir uma vantagem competitiva" ficou com a menor média, 5,12. Assim, por mais que a Cooperativa de Crédito e de Investimento possua produtos e serviços muito semelhantes as demais instituições bancárias, a disponibilidade inicial destes é um pouco mais lenta que as demais, 
pois precisa ser adaptada as suas normas e regras internas, não podendo estar em desacordo com a cultura local, que é importantíssima para a Cooperativa.

O construto Vantagem Competitiva ficou com a segunda melhor média, fato que não é visto com frequência em estudos semelhantes, nesse sentido, Oliveira Filho et al. (2014) apresentou um estudo com as mesmas dimensões, ficando Capital Relacional com média igual a 5,15, Capital Humano com média igual a 5,12, Capital Estrutural com média igual a 4,84 e por fim Vantagem Competitiva com média igual a 4,83, da mesma forma, Porter (1989) menciona que é de se esperar notas menores para a dimensão deste constructo, informando que isto não significa que a empresa não possua vantagem competitiva.

Vale destacar que a Cooperativa pesquisada possui pouco mais de 25 anos de atuação, sendo que a cada ano vem crescendo mais, nesse sentido, Leite e Porsse (2003), afirma que a vantagem competitiva pode ser conceituada como a ocorrência de níveis de performance econômica acima da média do mercado em virtude das estratégias diferenciadas adotadas pelas empresas.

\subsection{VALORES MÉDIOS DAS DIMENSÕES}

O Gráfico 1 ilustra as notas médias atribuídas aos tipos de capital e à vantagem competitiva, sendo estes a base da formação do capital intelectual, o gráfico foi desenvolvido com base nos resultados médios obtidos em cada dimensão pesquisada.

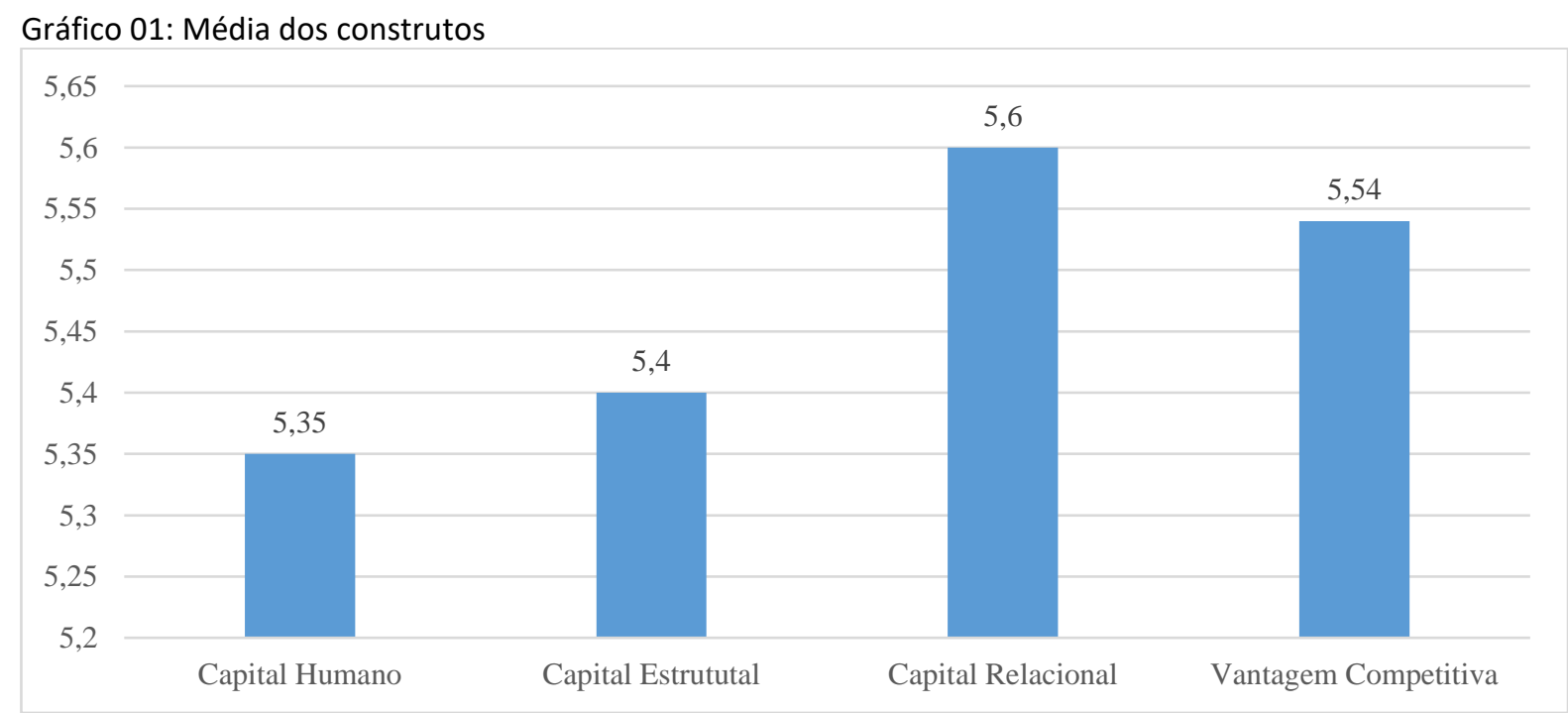

Fonte: Dados da pesquisa

Conforme demonstra o Gráfico 1, a dimensão Capital Relacional ficou com média igual a 5,60, seguido pela dimensão do construto Vantagem Competitiva com média igual a 5,54, após, ficou a dimensão Capital Estrutural com média igual a 5,4 e por fim a dimensão Capital Humano com média igual a 5,35.

\subsection{ANÁLISE FATORIAL EXPLORATÓRIA - DIMENSIONALIDADE E CONFIABILIDADE DAS ESCALAS}

O teste de dimensionalidade do construto foi realizado por meio da Análise Fatorial Exploratória com extração dos componentes principais. De acordo com Hair Jr. et al. (2005), a inclusão dos itens no construto foi feita no caso deles possuírem carga fatorial mínima e 
0,7 e, consequentemente, uma comunalidade aproximada de 0,50 e a medida de adequação da amostra (MSA) acima de 0,50.

A fim de identificar o conjunto de dimensões latentes nos dados, empregou-se o critério de KMO (Kaiser-Meier-Olkin), qual exigia valores iguais ou superiores a 0,5; o teste de esfericidade de Bartlett, que deveria apresentar valor de $p \leq 0,05$; e alfa de Cronbach, que deveria apresentar igual ou superior a 0,70. Além disso foram analisadas a variância total explicada dos construtos que deveria representar ao menos 50\%, e o autovalor extraído do fator 1, que deveria apresentar o valor mínimo de 1. A Tabela 5 apresenta os resultados da análise fatorial exploratória para cada um dos construtos.

Tabela 5 - Resultados da Análise Fatorial Exploratória

\begin{tabular}{c|c|c|c|c|c}
\hline Construto & KMO & $\begin{array}{c}\text { Teste de } \\
\text { Bartlett }\end{array}$ & $\begin{array}{c}\text { Alfa de } \\
\text { Cronbach }\end{array}$ & $\begin{array}{c}\text { Autovalor } \\
\text { extraído }\end{array}$ & $\begin{array}{c}\text { \% variância } \\
\text { explicada }\end{array}$ \\
\hline Capital intelectual & 0,915 & $\mathrm{p}=0,000$ & 0,960 & 6,105 & 74,985 \\
\hline $\begin{array}{c}\text { Vantagem } \\
\text { Competitiva }\end{array}$ & 0,899 & $\mathrm{p}=0,000$ & 0,938 & 5,671 & 70,882 \\
\hline
\end{tabular}

Fonte: Dados da pesquisa

Ao realizar a análise fatorial exploratória (AFE) com a rotação Varimax observou-se que todos os valores estão adequados. O KMO e o tese de Bartlett para os dois construtos representa a adequação dos dados. Além disso, o teste de Alpha de Cronbach representa a consistência e a confiabilidade do instrumento, já que este foi utilizado a partir de uma escala internacional. Assim, o instrumento pode ser considerado confiável, mensurando o que foi proposto a medir.

A estrutura apresentada na análise dos fatores do construto capital intelectual extraiu os três fatores, conforme apresenta o modelo proposto neste estudo. Já a análise da Vantagem Competitiva apresentou apenas a extração do único fator. Sendo assim, a Tabela 6 apresenta os resultados para a variância dos indicadores do capital intelectual.

Tabela 6 - Variância explicada na AFE dos indicadores do capital intelectual

\begin{tabular}{|c|c|c|c|c|c|c|}
\hline \multicolumn{7}{|c|}{ Variância Total Explicada } \\
\hline \multirow[b]{2}{*}{ Fator } & \multicolumn{3}{|c|}{ Autovalores iniciais } & \multicolumn{3}{|c|}{ Autovalores retidos (cargas) } \\
\hline & Total & \% da variância & $\%$ cumulativo & Total & \% da variância & $\%$ cumulativo \\
\hline 1 & 11,513 & 57,567 & 57,567 & 6,105 & 30,526 & 30,526 \\
\hline 2 & 2,194 & 10,968 & 68,535 & 4,765 & 23,826 & 54,352 \\
\hline 3 & 1,290 & 6,450 & 74,985 & 4,126 & 20,632 & 74,985 \\
\hline
\end{tabular}

Fonte: Dados da pesquisa

Este percentual indica a capacidade de explicação dos três fatores do capital intelectual, entretanto foram verificadas diversas cargas cruzadas acima de 0,3 , as quais são consideradas altas e podem representar que determinada dimensão é explicada por mais de 1 fator. Por isso, para melhorar a avaliação das escalas, foram retirados os indicadores que possuíam altas cargas cruzadas. Ressalta-se que a exclusão de cargas menores do que 0,5 foram utilizadas. Das 20 variáveis observáveis propostas inicialmente para mensuração do capital intelectual, a solução final encontrada para este construto é composta por 13 variáveis, conforme demonstra a Tabela 7. 
Tabela 7 - Análise fatorial exploratória do construto capital intelectual após purificação

\begin{tabular}{|c|c|c|c|c|c|}
\hline Fator & Indicador & 1 & 2 & 3 & Comunalidades \\
\hline \multirow{3}{*}{ Capital Humano } & Ch01 & $*$ & $*$ & 917 & 919 \\
\hline & Ch02 & $*$ & $*$ & 913 & ,939 \\
\hline & Ch03 & $*$ & $*$ & ,880 & 913 \\
\hline \multirow{4}{*}{ Capital Estrutural } & Ch05 & $*$ & ,814 & $*$ & ,779 \\
\hline & Ch06 & $*$ & ,847 & $*$ & ,846 \\
\hline & Ch07 & $*$ & ,850 & $*$ & ,811 \\
\hline & $\mathrm{CeO8}$ & $*$ & ,741 & $*$ & ,717 \\
\hline \multirow{6}{*}{ Capital Relacional } & Ce10 & ,571 & $*$ & $*$ & ,603 \\
\hline & Ce11 & 741 & $*$ & $*$ & ,762 \\
\hline & Cr15 & 913 & $*$ & $*$ & ,861 \\
\hline & Cr16 & 906 & $*$ & $*$ & ,858 \\
\hline & Cr17 & ,849 & $*$ & $*$ & ,819 \\
\hline & $\mathrm{Cr} 20$ & ,795 & $*$ & $*$ & \\
\hline \multicolumn{2}{|c|}{ Autovalor } & 4,231 & 3,303 & 3,027 & \\
\hline \multicolumn{2}{|c|}{ Variância \% } & 32,550 & 25,410 & 23,288 & \\
\hline \multicolumn{2}{|c|}{ Acumulada \% } & 32,550 & 57,960 & 81,247 & \\
\hline
\end{tabular}

Após a exclusão de variáveis que apresentavam altos índices de carga cruzada, o construto capital intelectual ficou composto por treze variáveis e três dimensões. Percebe-se que duas dimensões (criatividade e abertura para mudanças) puderam ser explicadas por um único fator diferentemente do que foi proposto por Shoham et al. (2012). Neste caso, as dimensões capital humano e capital estrutural foram transformadas em um único fator, assim como uma variável do capital estrutural também entrou no fator capital relacional.

A seguir a Tabela 8 apresenta a matriz de correlação entre as variáveis, por meio da realização do Teste de Correlação de Pearson. A partir da análise da Tabela é possível identificar uma alta correlação entre todas as variáveis do estudo, indicando que todas as variáveis estão correlacionadas significativamente entre si. Além disso, destaca-se que as variáveis das dimensões do capital intelectual influenciam positivamente na vantagem competitiva da organização em estudo.

Sendo assim, infere-se que a vantagem competitiva pode ser influenciada pela adequada gestão e práticas que fomentem o capital intelectual das organizações, visto que este resultado ficou evidenciado a partir deste estudo. 
Tabela 8 - Matriz de correlação entre as variáveis

\begin{tabular}{|c|c|c|c|c|c|c|c|c|c|c|c|c|c|c|c|c|c|c|c|c|}
\hline Correlações & Ch01 & Ch02 & Ch03 & Ch05 & Ch06 & Ch07 & $\mathrm{CeO8}$ & Ce11 & Cr15 & Cr16 & Cr17 & $\mathrm{Cr} 20$ & VC21 & VC22 & VC23 & VC24 & VC25 & VC26 & VC27 & VC28 \\
\hline Ch01 & 1 & & & & & & & & & & & & & & & & & & & \\
\hline Ch02 & ,901 & 1 & & & & & & & & & & & & & & & & & & \\
\hline Ch03 &, $863^{* *}$ &, $902^{* *}$ & 1 & & & & & & & & & & & & & & & & & \\
\hline Ch05 &, $374^{* *}$ & $477^{* *}$ &, $511^{* *}$ & 1 & & & & & & & & & & & & & & & & \\
\hline Ch06 &, $426^{* *}$ & ,488** &, $543^{* *}$ &, $777^{* *}$ & 1 & & & & & & & & & & & & & & & \\
\hline Ch07 &, $416^{* *}$ &, $454^{* *}$ &, $500^{* *}$ & ,680** &, $808^{* *}$ & 1 & & & & & & & & & & & & & & \\
\hline $\mathrm{Ce} 08$ &, $486^{* *}$ & ,560** &, $532^{* *}$ & $685^{* *}$ & ,640** & ,694** & 1 & & & & & & & & & & & & & \\
\hline Ce11 &, $524^{* *}$ &, $517^{* *}$ & ,499** & $475^{* *}$ &, $519^{* *}$ & $468^{* *}$ &, $518^{* *}$ & 1 & & & & & & & & & & & & \\
\hline Cr15 & ,302 &, $276^{* *}$ &, $276^{* *}$ & $423^{* *}$ &, $376^{* *}$ &, $365^{* *}$ & , $344^{* *}$ &, $723^{* *}$ & 1 & & & & & & & & & & & \\
\hline Cr16 & ,335 &, $282^{* *}$ &, $251^{*}$ &, $441^{* *}$ &, $405^{* *}$ & ,384** & $375^{* *}$ & ,680** & ,890** & 1 & & & & & & & & & & \\
\hline Cr17 &, $351^{* *}$ & $321^{* *}$ &, $358^{* *}$ &, $480^{* *}$ &, $519^{* *}$ & $436^{* *}$ &, $431^{* *}$ & ,640** & ,787** & ,809** & 1 & & & & & & & & & \\
\hline $\mathrm{Cr} 20$ &, $383^{* *}$ &, $365^{* *}$ & $408^{* *}$ & $465^{* *}$ & $499^{* *}$ &, $418^{* *}$ &, $401^{* *}$ &, $758^{* *}$ & ,675 &, $723^{* *}$ & ,709** & 1 & & & & & & & & \\
\hline VC21 &, $579^{* *}$ &, $577^{* *}$ &, $537^{* *}$ &, $544^{* *}$ &, $678^{* *}$ & $686^{* *}$ & $646^{* *}$ &, $713^{* *}$ &, $536^{* *}$ & ,607 & $604^{* *}$ &, $645^{* *}$ & 1 & & & & & & & \\
\hline VC22 &, $516^{* *}$ &, $527^{* *}$ &, $573^{* *}$ &, $623^{* *}$ & ,730** &, $727^{* *}$ & ,682 &, $674^{* *}$ &, $594^{* *}$ & ,627 &, $662^{* *}$ &, $665^{* *}$ &, $871^{* *}$ & 1 & & & & & & \\
\hline VC23 &, $522^{* *}$ &, $518^{* *}$ & $496^{* *}$ &, $523^{* *}$ &, $578^{* *}$ &, $526^{* *}$ &, $578^{* *}$ & ,784** & ,628** & ,692 & $650^{* *}$ & ,651 &, $757^{* *}$ &, $763^{* *}$ & 1 & & & & & \\
\hline VC24 &, $586^{* *}$ &, $596^{* *}$ & ,600** & $458^{* *}$ &, $554^{* *}$ & $494^{* *}$ & ,524** & ,624 &, $536^{* *}$ & ,519** & ,610** &, $565^{* *}$ &, $634^{* *}$ & ,707** & ,706 & 1 & & & & \\
\hline VC25 &, $520^{* *}$ &, $525^{* *}$ & $477^{* *}$ & $474^{* *}$ &, $536^{* *}$ & $476^{* *}$ &, $518^{* *}$ & ,690** &, $651^{* *}$ &, $628^{* *}$ & ,689** &, $554^{* *}$ &, $752^{* *}$ &, $740^{* *}$ & ,773** &, $753^{* *}$ & 1 & & & \\
\hline VC26 &, $436^{* *}$ & , $487^{* *}$ &, $435^{* *}$ &, $585^{* *}$ & ,629** & ,682 & ,624 & ,623** &, $516^{* *}$ &, $505^{* *}$ &, $509^{* *}$ &, $447^{* *}$ & ,700** & ,720** & ,644 & ,639** & ,688** & 1 & & \\
\hline VC27 &, $400^{* *}$ &, $472^{* *}$ &, $481^{* *}$ & ,640 & , $667^{* *}$ & ,751 & ,680** &, $513^{* *}$ & $440^{* *}$ &, $432^{* *}$ &, $504^{* *}$ & $448^{* *}$ & ,677 & ,739** &, $572^{* *}$ & ,598** &, $587^{* *}$ & $812^{* *}$ & 1 & \\
\hline VC28 & ,306 &, $318^{* *}$ &, $355^{* *}$ &, $427^{* *}$ & $418^{* *}$ & ,534 & ,502 &, $573^{* *}$ &, $421^{* *}$ &, $392^{* *}$ & ,390** & $442^{* *}$ &, $547^{* *}$ &, $536^{* *}$ &, $491^{* *}$ & $423^{* *}$ & $485^{* *}$ &, $593^{* *}$ & ,658 & 1 \\
\hline
\end{tabular}

Fonte: Dados da pesquisa

** correlação significativa a 0,01 


\section{CONSIDERAÇÕES FINAIS}

O presente artigo buscou mensurar o impacto do capital intelectual sobre a vantagem competitiva, a partir da visão dos colaboradores de uma cooperativa de crédito e de investimento do sul do país.

Portanto, a partir dos resultados obtidos na pesquisa, verificou-se que as três dimensões do capital intelectual possuem influência sobre a vantagem competitiva da cooperativa de crédito em estudo.

Esse resultado pode ser proveniente devido a forma de relacionamento da Cooperativa de Crédito e de Investimento para com seus cooperados, por meio da oferta de um ambiente propício, com motivação e recompensas para troca de conhecimentos e informações entre os colaboradores, o que foi evidenciado a partir da análise da dimensão de capital relacional. Além disso, a empresa valoriza as ideias dos colaboradores e incentiva que eles troquem ideias entre si para diagnosticar e resolver problemas.

No que se refere ao capital estrutural vale destacar que a cooperativa possui uma infraestrutura adequada para armazenamento e busca de conhecimentos desenvolvidos pelos colaboradores. Neste sentido, a cooperativa possui uma cultura que incentiva o uso do conhecimento disponível para resolver problemas e aproveitar as oportunidades que surgem no ambiente

Além disso, vale salientar que a organização investe fortemente em treinamento de seus colabores a fim de difundir o conhecimento na organização, o que pode ser evidenciado na dimensão capital humano. Também, enfatiza-se que os gestores valorizam as competências individuais de cada colaborador, e acreditam que possuem as melhores pessoas nos seus respectivos cargos de trabalho.

Essas constatações levam, portanto, à conclusão de que o capital intelectual contribui para a criação e manutenção da vantagem competitiva, visto que a empresa consegue alcançar uma posição superior no mercado se comparada as suas concorrentes.

De acordo com o evidenciado na pesquisa, isto pode ser resultado das boas práticas de gestão do capital intelectual utilizados pela cooperativa de crédito em análise.

Porém por se tratar de um tema consideravelmente novo pela literatura, existem ainda algumas lacunas a serem estudadas, principalmente no desenvolvimento e gestão do capital intelectual para criação e manutenção de vantagens competitivas.

Por fim, considerando todo o conteúdo analisado e a posterior aplicação dos conhecimentos aqui pesquisados, haverá contribuição para a melhoria na Cooperativa de Crédito e de Investimento, na sua gestão do capital intelectual. Além disso, o artigo almeja servir de referencial para futuras pesquisas sobre temática, contribuindo, sobremaneira, para a difusão deste tema extremamente relevante nos dias atuais.

Algumas limitações foram verificadas na confecção deste artigo, dentre elas, destacase a delimitação da amostra, sugere-se a ampliação desse público-alvo para que seja possível entender como a percepção de capital intelectual e a vantagem competitiva permeiam toda a organização, e para que outras organizações também possam ser avaliadas, inclusive comparando-se culturas, regiões e até países diferentes.

Apontada essas limitações, cabe ressaltar que a literatura tem destacado que o capital intelectual é fonte de vantagem competitiva e, vem ao longo destes últimos anos trazendo várias pesquisas sobre o tema, verificando-se que empresas que tiveram um investimento e desenvolvimento do capital intelectual, obtiveram como resultado vantagens 
competitivas, tomadas de decisões mais precisas e consequentemente um maior resultado financeiro.

\section{REFERÊNCIAS}

ANTUNES, M, T, P. O capital intelectual segundo o entendimento de gestores de empresas brasileiras. Revista Brasileira de Gestão de Negócios, v. 7, n. 19, p. 9-20, 2005.

ANTUNES, M, T, P.; MARTINS, E. Capital intelectual: seu entendimento e seus impactos no desempenho de grandes empresas brasileiras. Revista de Administração e Contabilidade da UNISINOS, v. 4, n. 1, p. 5-21, 2007.

ANTUNES, M, T, P; MARTINS, E. Gerenciando o capital intelectual: uma proposta baseada na controladoria de grandes empresas brasileiras. Revista Eletrônica de Administração, v. 13, n. 1, p. 1-23, 2007.

ARAUJO, R, P.; MOTTIN, A, P.; REZENDE, J, F, C. Gestão do conhecimento e do capital intelectual: mapeamento da produção acadêmica brasileira de 1997 a 2011 nos encontros da ANPAD. Revista Organização \& Sociedade, v. 20, n. 65, p. 283-301, 2013.

ARAUJO, R, F.; ALVARENGA, L. A bibliometria na pesquisa científica da pós-graduação Brasileira de 1987 a 2007. Revista Eletrônica Biblioteconomia, v. 16, n. 31, p. 51-70, 2011.

BERTOLLA, F, L.; ECKERT, A.; DORION, E, C, H.; NODARI, C, H. Capital intelectual como recurso na retenção de clientes. Revista Contemporâneo em Administração, v. 9, n. 3, p. 155-168, 2015.

CARLOS FILHO, F, A.; LAGIOIA, U, C, T.; MONTEIRO, J, A, M.; SILVA FILHO, L, L.; ARAUJO, J, G.; ARAUJO, J, G, N. Importância e contribuição do ativo intangível: percepção dos empreendedores de micro e pequenas empresas sobre o capital intelectual. Revista Organizações em contexto, v.10, n. 20, p. 1-27, 2014.

COSER, A. Modelo para análise da influência do capital intelectual sobre a performance dos projetos de software. Tese (Doutorado em Engenharia e Gestão do Conhecimento) Programa de Pós-Graduação em Engenharia e Gestão do Conhecimento, Universidade Federal de Santa Catarina, Florianópolis, 2012.

COSER, A.; MORALES, A, B, T.; SELIG, P, M. A influência do capital intelectual sobre a performance dos projetos de software. Revista Perspectivas em Gestão \& Conhecimento, v. 3, n. 2, p. 196-217, 2013.

EDVINSSON, L.; LEW, M. B. Intellectual Capital at Skandia. Ernst \& Young Center for Information Technology and Strategy, 1999.

ENSSLIN, S, R.; CARVALHO, F, N.; GALLON, A, V.; ENSSLIN, L. Uma metodologia multicritério (MCDA-C) para apoiar o gerenciamento do capital intelectual organizacional. Revista de Administração Mackenzie, v. 9, n. 7, p. 136-163, 2008. 
GALLON, A, V.; ENSSLIN, S, R.; SOUZA, F, C.; ROVER, S. Capital intelectual: análise bibliométrica e mapeamento da pesquisa no período de 2000 a 2006 em três fóruns brasileiros. Revista Organizações em contexto, v. 4, n. 8, p. 49-73, 2008.

GALLON, A, V.; SOUZA, F, C.; ROVER, S.; ENSSELIN, S, R. Um estudo reflexivo da produção científica em capital intelectual. Revista de Administração Mackenzie, v. 9, n. 4, p. 142-172, 2008.

GIL, A, C. Métodos e técnicas de pesquisa social. 5. ed. São Paulo: Atlas, 1999.

GODOY, A.S. Introdução à pesquisa qualitativa e suas possibilidades. Revista de Administração de Empresas da EAESP/FGV, v. 35, n. 2, p. 57-63, 1995.

HAIR JR., J. F.; BABIN, B.; MONEY, A. H.; SAMOUEL, P. Fundamentos de métodos de pesquisa em administração. Porto Alegre: Bookman, 2005.

JOIA, L, A.; MALHEIROS, R.; Evidências empíricas da influência de alianças estratégicas no capital intelectual de empresas. Revista de Administração e Contabilidade da Unisinos, v. 7, n. 2, p. 162-177, 2010.

LEITE, J. B. D.; PORSSE, M. C. S. Competição baseada em competências e aprendizagem organizacional: em busca da vantagem competitiva. Revista de Administração Contemporânea, v. 7, n. spe., p. 121-141, 2003.

OLIVEIRA FILHO, J, B.; LOPES, J, E, F.; OLIVEIRA, M, F. O efeito da gestão do capital intelectual na vantagem competitiva: o caso de um grupo empresarial com atuação predominante em tecnologia. Revista Gestão Organizacional, v. 7, n. 2, p. 89-101, 2014.

ORO, I, M.; BALBINOT, I, J.; THOMÉ, D.; LAVARDA, C, E, F. Relação do capital intelectual de natureza social e ambiental com o desempenho econômico financeiro do segmento de energia elétrica brasileiro. Revista de Administração da UFSM, v. 7, Edição Especial, p. 5974, 2014.

REINA, D.; ENSSLIN, S, R.; GALLON, A, V.; REINA, D, R, M. Investigação da produção científica sobre capital intelectual: um estudo entre os anos de 1996 e 2006 em publicações da área contábil. Revista Gestão Organizacional, v. 2, n. 2, p. 108-122, 2009.

REIS, L, G. As dificuldades de mensuração e consequente divulgação nas demonstrações contábeis do capital intelectual: uma reflexão teórica. Revista Contabilidade Vista \& Revista, v. 16, n. 2, p. 43-60, 2005.

RICHARDSON, R, J. Pesquisa social: métodos e técnicas. 3. ed. São Paulo: Atlas, 1999.

RONCHI, S, H.; ENSSELIN, A. R.; Investigação da produção científica sobre capital intelectual entre os anos de 2000 e 2006 em 12 periódicos Internacionais do portal

CAPES. Revista Gestão \& Regionalidade, v. 23, n. 68, p. 70-80, 2007. 
ROOS, J. PIKE, S. FERNSTREM, L. Intellectual capital: practice of management. Saint Peterburg: Higher School of Management, 2008.

SHARON, B. Using intellectual capital and organizational capability to enhance strategic implementation for pharmaceutical firms. Journal of Business and Public Affairs, v. 1, n. 1, 2007.

STEWART, T. A. Capital intelectual: a nova vantagem competitiva das empresas. 14. ed. Elsevier Editora Ltda, 1998.

TEODOROSKI, R, C, C.; MACHADO, E.; INOMATA, D, O.; FOLLMANN, N. Contribuição do capital intelectual no compartilhamento em uma rede de ensino superior. Revista de Gestão e Tecnologia - NAVUS, v. 3, n. 2, p. $105-113,2013$.

TURRA, S.; VERGINI, D, P.; JACOMOSI, F, A.; HEIN, N. Efeitos do capital intelectual sobre o desempenho financeiro em empresas brasileiras e chilenas. Contextus - Revista Contemporânea de Economia e Gestão, v. 13, n. 2, p. 84-104, 2015.

VANTI, N, A, P. Da bibliometria à webometria: uma exploração conceitual dos mecanismos utilizados para medir o registro da informação e a difusão do conhecimento. Ciência da Informação, v. 31, n. 2, p. 152-162, 2002.

VAZ, C. R.; INOMATA, D, O.; VIEGAS, C, V.; SELIG, P, M.; VARVAKIS, G. Capital intelectual: classificação, formas de mensuração e questionamento sobre usos futuros. Revista de Gestão e Tecnologia - NAVUS, v. 5, n. 2, p. 73-92, 2015.

ZHENG, W.; YANG, B.; MCLEAN, G. N. Linking organizational culture, structure, strategy, and organizational effectiveness: mediating role of knowledge management. Journal of Business Research, v. 63, n. 7, p. 763-771, 2010.

YOUNDT, M. A.; SUBRAMANIAM, M.; SNELL, S. A. Intellectual capital profiles: an examination of investments and returns. Journal of Management Studies, v. 41, n. 2, p. 335-361, 2004. 